\title{
Avaliação do grau de implantação do Programa de Qualificação da Atenção Hospitalar de Urgência (Qualisus)
}

\author{
Implementation degree assessment \\ of the Hospital Urgency Care Qualification Program (Qualisus)
}

Fernando Antônio Ribeiro deGusmão-filho ${ }^{1}$

Eduardo Freese de Carvalho ${ }^{1}$

JoséLuiz do Amaral Correia deAraújo Júnior ${ }^{1}$

Abstract This study aims to assess the implementation degree of the Hospital U rgency Care Qualification Program (Qualisus) in three high complexity hospitals of Recife municipality, Pernambuco State. A normativeassessment was conducted based on structural and work process attributes concerning to user rights and embracement and to health services diagnostic and therapeutic resolubility. The program implementation degree was evaluated as intermediate at the three hospitals. Results referred to the implementation degree of program actions are described and discussed in detail in this article.

Key words Program assessment. Q uality of health care, Emergency services
Resumo 0 presenteartigo tem por objetivo avaliar o grau de implantação do Programa deQualificação da A tenção H ospitalar deU rgência (Q ualisus) em três hospitais de alta complexidade do SUS do município do Recife, Pernambuco. Foi realizada uma avaliação normativa, levando-se em conta atributos estruturais e do processo de trabaIho relativos às dimensões do acolhimento e direitos dos usuários e da resolutividade diagnóstica e terapêutica dos serviços. 0 grau de implantação do programa foi avaliado como intermediário nos três hospitais. 0 artigo detalha e discute os achados referentes ao grau de implantação das ações que compõem o programa nos três serviços.

Palavras-chave Avaliação deprogramas, Q ualidade da assistência à saúde, Serviços de emergência
${ }^{1}$ Centro de Pesquisas Aggeu M agalhães, Fiocruz. Av. Professor M oraes Rego $\mathrm{s} / \mathrm{n}$, Cidade Universitária. 50670-420 Recife PE. fgusmaofilho@gmail.com 
Introdução

Em conformidadecom o Plano N acional de Saúde, foi definida a chamada Política de Q ualificação da A tenção à Saúde do Sistema Ú nico de Saúde, denominada Qualisus. Esta foi lançada publicamente em 2003, com o objetivo central de elevar o nível de qualidade da assistência prestada à população pelo SUS, representando assim a síntese das aspirações e necessidades da população de uma atenção à saúde que garanta 0 acesso a todos os níveis de complexidadee, principalmente, uma atenção eficaz, efetiva e humana como parte de seus direitos de cidadania ${ }^{1}$.

Dentre oS vários componentes do SUS, OS serviços de urgência e emergência das grandes capitais foram considerados como prioritários no processo de qualificação, com a justificativa de serem reconhecidos como uma das principais fontes de queixas da população, segundo pesquisa de opinião $0^{2,3}$. D efine-se correntemente urgência como "a ocorrência imprevista de agravo à saúde com ou sem risco potencial de vida, cujo portador necessita de assistência médica imediata" e emergên cia como "a constatação médica de condições de agravo à saúde que impliquem em risco iminente de vida ou sofrimento intenso, exigindo, portanto, o tratamento médico imediato" 4 . A superlotação das portas hospitalares de urgência seria decorrente de vários fatores, dentre os quais se destacam a baixa resolutividade da rede primária, a desarticulação entre os níveis deassistência ea própria insuficiência estrutural, gerencial efuncional destes serviços ${ }^{5,6}$.

Ao priorizar a qualificação dos sistemas de urgências, o Qualisus entra em consonância com a Política Nacional de Atenção às Urgências (PNAU), que pressupõe para este fim: (1) a organização de rede não hospitalar de urgência na atenção básica e numa rede de pronto-atendimentos; (2) o desenvolvimento do atendimento pré-hospitalar de urgência, pela implantação do Serviço M óvel deUrgência (Samu); (3) a instalação de uma central geral de regulação de leitos (Regulação M édica); (4) a organização equalificação dos hospitais de urgência para dar suporteresolutivo ao sistema deurgência; (5) a definição de retaguarda de leitos hospitalares e atenção domiciliar ${ }^{1,7}$.

O Qualisus estátambém em consonância com a Política Nacional de Humanização (PNH) , que destaca a humanização como dimensão fundamental do cuidado com qualidade à saúde. Esta política prevê a redução de filas e do tempo de espera, a ampliação do acesso, 0 atendimento acolhedor de acordo com a gravidade, a referência territorial, a garantia deinformações ao usuário e de acompanhamento por pessoas de sua rede social e a garantia de gestão participativa ${ }^{8}$.

Assim, o Qualisus, enquanto política de saúde dirigida fundamentalmente aos sistemas de urgências, prevêinvestimentosem equipamentos e infraestrutura, na formação e val orização dos trabalhadores, nas propostas de mudanças nas inter-relações entre profissionais de saúdeeusuários e na introdução denovas tecnologias organizacionais de atenção e de novos modelos de gestão nas portas hospitalares de urgência ${ }^{5}$. Dessa forma, visando a sua implantação, o Qualisus passa a ser um programa do M inistério da Saúde dirigido ao sistema de urgência e emergência?.

O conteúdo e a metodologia de implantação do Qualisus foram desenvolvidos a partir da reunião de experiências regionais de qualificação assistencial, em todo o país, por uma equipetécnica reunida sob coordenação ligada à Secretaria Executiva e participante do colegiado gestor do M inistério da Saúde. A sua implantação foi iniciada em 2004, a partir de uma experiência piloto em quatro capitais: Porto Alegre, Rio de Janeiro, Goiânia e Recife. Em meados do segundo semestre de 2005, o programa foi expandido para as demais capitais e regiões metropolitanas ${ }^{1,5,6}$.

A implantação foi precedida pela discussão da proposta entre o M inistério da Saúde, os estados eos municípios, seguida do estabelecimento de um pacto de compromisso entre as esferas, com definição de papéis e contrapartidas. As secretarias estaduais e municipais se encarregariam fundamentalmente do gerenciamento da implantação da política na rede assistencial local, garantindo insumos e a contratação de recursos humanos quando necessário. Ao M inistério da Saúde caberia o financiamento para reformas físicas e aquisição de equipamentos pelos hospitais. A negociação foi firmada pela assinatura de um protocolo de intençõe ${ }^{1,5,6}$.

Em cada região metropolitana, foram preferencialmente selecionados hospitais gerais com porta hospitalar de urgência, pertencentes à rede própria do SUS. Alguns hospitais universitários e filantrópicos também foram incluídos, com a justificativa de causar impacto significativo no sistema de saúde. Em Pernambuco, a segunda maior rede pública hospitalar do SUS, foram incluídos o H ospital da Restauração (HR), o H ospital Geral Otávio deFreitas (HGOF) e o Hospital Getúlio Vargas (HGV), classificados como hospitais de referência de nível III, ou seja, de média e alta complexidade ${ }^{1,5,6}$. 
O processo de implantação do Qualisus pactuado com os hospitais era composto por quatro eixos:

(1) Acolhimento, ambiência e direito dos usuários - que reúne linhas de ação sob a dimensão da humanização, com vistas ao respeito ao direito das pessoas, ao conforto dos usuários e à sua adaptação aos serviços de saúde;

(2) Resolução diagnóstica eterapêutica - que contém linhas de ação visando à efetividade e à resolutividade da assistência à saúde, a valorização dos trabal hadores e a redução dos riscos;

(3) Responsabilização egarantia de continuidade do cuidado - quetraz linhas de ação direcionadas à presteza da aten ção e ao fortal ecimento do vínculo dostrabalhadores com usuáriosecom o sistema de saúde e

(4) A primoramento edemocratização da gestão - que agrupa linhas de ação objetivando uma maior capacidade de gestão e controle social dos hospitais e setores de urgências ${ }^{1,5}$.

Assim, o programa Qualisus carrega no seu bojo um conjunto de conceitos complementares baseados em pilares fundamentais do SU S, como a equidade ea integralidade das ações, relacionadas à humanização do cuidado. Cabe lembrar que muitas de suas linhas de ação não são exclusivas, tomando parte de outras políticas, como a PNH, eaté mesmo de programas de qualificação próprios dos hospitais. 0 processo de implantação do Qualisus, assim como o de qualquer outro programa, pode sofrer interferência dos atores envolvidos, consultores, gestores estaduais, municipais ehospitalares e dos trabal hadores de saúde, agindo em contextos distintos em relação às características dos hospitais, do sistema de saúde e às diversidades socioeconômico-culturais. 0 objetivo deste artigo é avaliar o grau de implantação do programa Qualisus em três hospitais do município do Recife, tendo como referência atributos relativos à estrutura (espaço físico, recursos materiais e humanos, estrutura organizacional) e ao processo de trabalho (aplicação de rotinas, protocolos enormalizações) das suas próprias linhas de ação.

\section{Métodos}

Os hospitais incluídos no estudo são classificados como hospitais gerais com porta hospitalar de urgência, por atenderem à demanda tanto de urgência como eletiva, de caráter geral e especializado, espontânea e referenciada. Apesar de pertencerem à mesma categoria, estes hospitais têm perfis diferentes e papéis distintos na redede assistência à saúde local. 0 H R possui a porta de urgência deadultosmaisutilizada do estado, com cerca de 12,5 mil atendimentos mensais à época do início da implantação do programa. É referência para casos de acidentes e procedimentos complexos, como a atenção a queimados e neurocirurgias. O HGOF atende predominantemente casos clínicos de uma área bastante populosa da região sudoeste do Recifeedo município vizinho de Jaboatão dos Guararapes. É referência para urgências psiquiátricas e traumato-ortopédicas. Já o H GV localiza-se na região oeste do município, assistindo do mesmo modo a uma área bastantepopulosa do Recife, além demunicípioscircunvizinhos, a oeste eao norte. É referência para

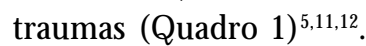

As variáveis selecionadas neste estudo para avaliação do grau de implantação foram definidas a partir das próprias linhas de ação reunidas nosEixosl (Acolhimento, ambiênciaedireito dos usuários) ell (Resolução diagnóstica e terapêutica). Três das linhas de ação do programa ainda não foram devidamente avaliadas e, portanto, não estão apresentadas neste artigo: a garantia de privacidade no atendimento, o direito de informação e confidencialidade das informações sobre o estado de saúde ea aplicação do Estatuto do I doso e da Criança e Adolescente.

A verificação do grau de implantação foi realizada por meio de avaliação normativa, quecompara os atributos das variáveis estudadas com critérios preestabelecidos ${ }^{10}$. 0 uso de padrões normativos são recomendados na pesquisa avaliativa quando resultantes de valores e conhecimentos aceitos pelo sistema de saúde vigente ${ }^{11}$. N o presenteestudo, os critérios e as normas adotadas foram derivados dos documentos oficiais do programa Qualisus e da PNAU 1,5,8,13,14.

Foi elaborado um sistema de pontuação atribuindo-se o mesmo peso aos eixos eàs linhas de ação dentro dos eixos. Dentro do Eixo I, a pontuação foi distribuída uniformemente entre as cinco linhas de ação (cinquenta pontos cada). A linha de ação "Acolhimento com classificação de risco" se refereà facilitação da adaptação do usuário ao serviço de saúde por uma equipe capacitada e à aplicação de critérios de gravidade para 0 atendimento. Leva em conta a adequação da área física, a quantidade e qualidade de recursos humanos e a aplicação de rotina de trabalho. A linha de ação "Garantia de usuário à alimentação adequada" refere-se ao fornecimento ao usuário das três refeições diárias principais. Já a linha de ação "Garantia ao usuário a acompa- 
nhante em consultas e área de observação" leva em conta a presença de mobiliário (pelo menos uma cadeira) e de sala de estar para os acompanhantes e a aplicação de rotina de trabalho. A linha de ação "Estabelecimento de visitas abertas com horários agendados pelos cuidadores" diz respeito à flexibilidade para troca de acompanhante, considerando a aplicação de rotina de trabalho. Por fim, a "Formação de Grupo deTrabalho de Humanização" reforça a necessi dade de equipes especialmente estabelecidas para a aplicação de concei tos e práticas relativas à humanização dentro da organização hospitalar, levando em conta a quantidade e capacitação de recursos humanos e a aplicação de rotina de trabalho.

O Eixo II, "Resolução diagnóstica eterapêutica", foi composto por setelinhas deação. Demodo arbitrário, a linha "Garantia de quantidade de profissionais adequados à demanda" recebeu quarenta pontos, enquanto que as demais, 35 pontos. Esta linha se refere à proporção percentual do número deprofissionais existentes em relação ao número de vagas existentes em cada serviço. A linha de ação "Normalização de condutas médicas" considera a elaboração e aplicação de guias de conduta médica e/ ou de enfermagem. A linha de ação "Adequação da estrutura física" leva em conta a divisão do setor de urgências em áreas de observação, de estabilização e de retaguarda, respeitando áreas e planejamento arquitetônico. Já a “Adequação de equipamentos na sala de estabilização e de retaguarda" considera a existência de uma lista mínima de aparel hagem em quantidade suficiente para suprir a demanda dos setores de urgência de cada hospital. A linha de ação "Organização de retaguarda de especialidades médicas de acordo com a demanda" refere-se à existência em número e composição suficientede equipes clínicas e cirúrgicas de apoio. Já a linha "Adequação do serviço de apoio diagnóstico eterapêutico de acordo com a demanda" considera a presença em quantidade suficiente desses serviços nos hospitais. Por fim, a linha de ação "Implantação de central de equipamentos de suportee monitoramento depacientes críticos" refere-seà existência desse serviço nos hospital, considerandoseainda o seu horário defuncionamento. 0 Quadro 2 resume 0 sistema de pontuação.

Quadro 1. Principais características dos setores de urgências dos H ospitais da Restauração (HR), Getúlio Vargas (H GV) e Geral Otávio de Freitas (H GOF), 2005.

\begin{tabular}{|c|c|c|c|}
\hline Características & $\mathrm{HR}$ & HGV & HGOF \\
\hline $\begin{array}{l}\text { Número de atendimentos } \\
\text { por mês }\end{array}$ & 12.500 & 12.000 & 11.000 \\
\hline $\begin{array}{l}\text { Número de médicos e } \\
\text { odontólogos por plantão }\end{array}$ & 31 & 25 & 20 \\
\hline $\begin{array}{l}\text { Número de leitos de } \\
\text { observação }\end{array}$ & 90 & 52 & 71 \\
\hline $\begin{array}{l}\text { Especialidades } \\
\text { (referência em itálico) }\end{array}$ & $\begin{array}{l}\text { Cirurgias geral (acidentados), } \\
\text { BM F, vascular, neurocirurgia; } \\
\text { clínica médica, neurologia; } \\
\text { traumatologia; endoscopia; } \\
\text { Ceatox; queimados. }\end{array}$ & $\begin{array}{l}\text { Cirurgiasgeral, BM F, } \\
\text { vascular e } \\
\text { neurocirurgia; clínica } \\
\text { médica, neurologia; } \\
\text { traumatologia. }\end{array}$ & $\begin{array}{l}\text { Cirurgia geral; } \\
\text { clínica médica; } \\
\text { pediatria; } \\
\text { psiquiatria. }\end{array}$ \\
\hline $\begin{array}{l}\text { Municípios de } \\
\text { procedência } \\
\text { dosusuários }\end{array}$ & $\begin{array}{l}\text { Recife: } 43,1 \% \\
\text { Olinda: } 12,0 \% \\
\text { Jaboatão: } 10,5 \% \\
\text { Paulista: } 6,1 \% \\
\text { Camaragibe: } 3,2 \% \\
\text { Outros: } 25,1 \%\end{array}$ & $\begin{array}{l}\text { Recife: } 64,0 \% \\
\text { Outrosmunicípios } \\
\text { da RM R: } 26,0 \% \\
\text { Demais municípiose } \\
\text { outros estados: } \\
\text { 10,0\% }\end{array}$ & $\begin{array}{l}\text { Jaboatão: } 46,6 \% \\
\text { Recife: } 41,4 \% \\
\text { Outros: } 12,0 \%\end{array}$ \\
\hline
\end{tabular}

Obs.: BM F: buco-maxilo-facial; Ceatox: Central detoxicologia; RM R: Região M etropolitana do Recife. 
Quadro 2. Pontuação conferida a linhas de ação e atributos dos Eixos I ell do programa Qualisus para avaliação do grau de implantação três hospitais do município do Recife, 2007.

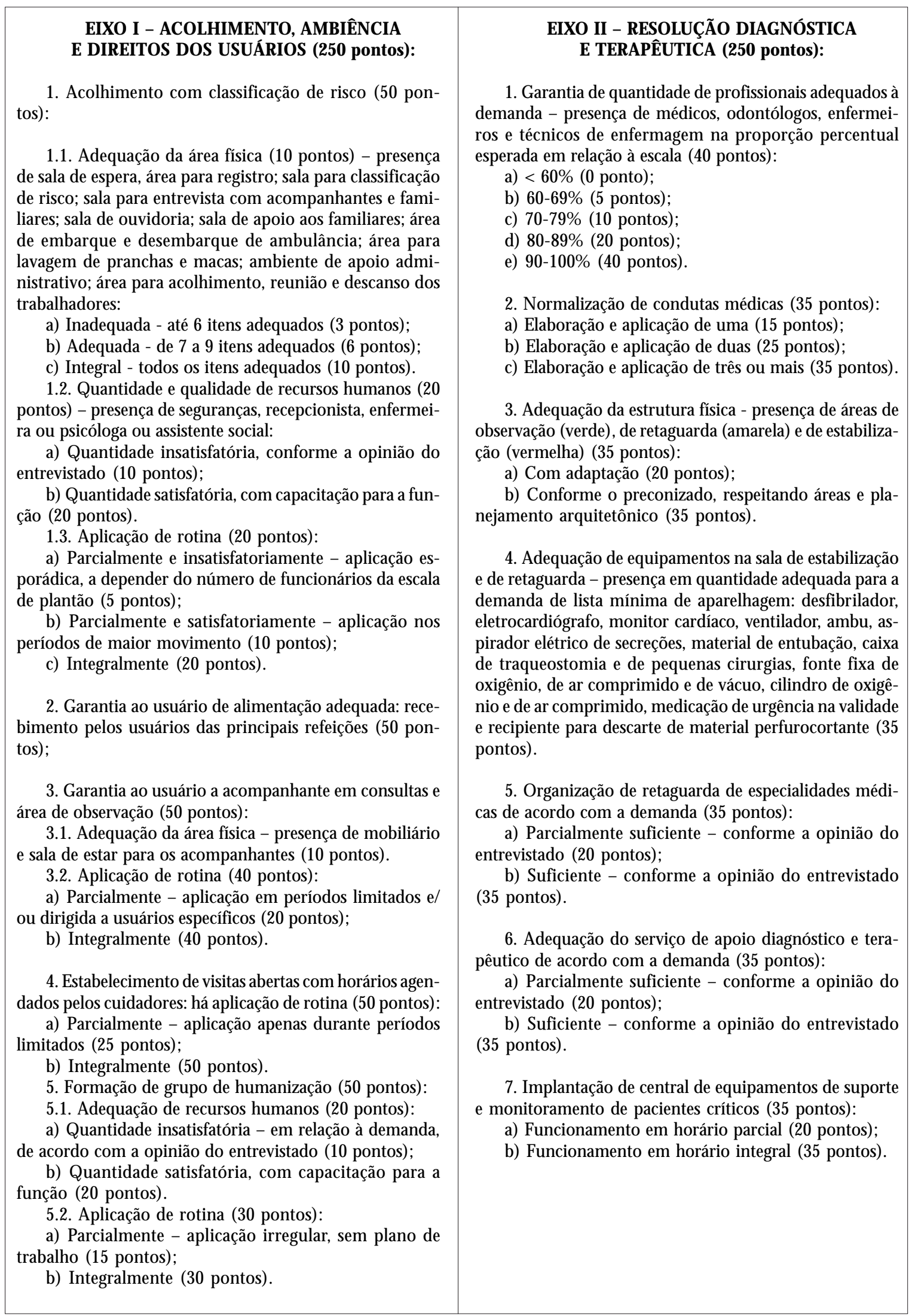


Tomou-se como grau de implantação a proporção da pontuação obtida em relação à pontuação máxima alcançável pelos hospitais para cada linha de ação, eixo e para o programa com um todo, conformeo sistema depontuação. Para a determinação do grau de implantação, foram arbitrariamente estabelecidos pontos de corte, de modo que os resultados obtidos apresentassem coerência - (1): 0 a 50\% - implantação incipiente; 51 a 75\% - implantação intermediária; 76 a 100\% - implantação avançada.

A coleta dos dados foi realizada pelo primeiro autor deste artigo por meio de questionário estruturado, contendo 59 perguntas fechadas relativas à qualidade e quantidade de elementos estruturais e à frequência e aplicação de rotinas. Foram entrevistados em cada hospital pelo me nos dois componentes da direção e/ou do setor de urgências, entre os meses de julho e setembro de2007, ou seja, dois anos após o início da introdução das melhorias. Na ocorrência de disparidades entre respostas, um terceiro ou até um quarto componente foi entrevistado.

Esteestudo foi submetido ao Comitê deÉtica e Pesquisa do Hospital da Restauração, aprovado sob o registro CAAE $n^{\circ}$ 0053.0.102.097-06. Os entrevistados assinaram o termo de consentimento livree esclarecido ao aceitarem participar da entrevista.

\section{Resultados ediscussão}

Considerando os dois eixos em conjunto, o grau de implantação foi considerado como intermediário nos três hospitais (HR - 73\%; HGOF $65 \%$; H GV - 57\%). A Tabela 1 e os gráficos 1 e 2 resumem a pontuação obtida e o grau de implantação correspondente para linhas de ação, eixos e hospitais. A seguir, serão apresentados e discutidos os resultados de cada eixo.

Eixo I - Acolhimento, ambiência e direito dos usuários

Este eixo reúne cinco linhas de ação sob a dimensão da humanização, relativas ao direito das pessoas, ao conforto dos usuários e a sua adaptação aos serviços de saúde. 0 grau de implantação do Eixo I foi considerado como avançado no HR (78\%), intermediário no HGOF (69\%) eincipiente no H GV (40\%) (Gráfico 1).

A linha de ação "Acolhimento com classificação de risco" apresentou implantação intermediária no HR (52\%) e incipiente no H GV (42\%) e no HGOF (6\%), como mostra o Gráfico 2. Essa linha deação tenta responder aum dos principais motivos de insatisfação dos usuários do SUS, de acordo com pesquisas recentes - a baixa acol hida por parte dos profissionais de saúde ${ }^{2,3}$. A noção de acolhimento, quando aplicada no campo da saúde, pressupõea mudança da relação profissional-usuário e profissional-profissional mediante parâmetros técnicos, éticos, humanitários e de solidariedade, levando ao reconhecimento do usuário como sujeito e participante ativo no processo de produção da saúde ${ }^{15-18}$. O Qualisus aplica a noção de acolhimento nos setores de urgências hospitalares, enfatizando o seu significado de ação gerencial de reorganização do processo de trabalho, por meio da instituição de espaço físico definido e de equipe capacitada para a aplicação de normalizações e rotinas especializadas. Entre essas, destaca-se a classificação de risco, uma ferramenta detriagem de largo emprego internacional, que confere agilidade do atendimento a partir da análise da gravidade, do potencial de risco ou do grau de sofrimento do usuário, ao invés da simples ordem de chegada no serviço ${ }^{19-21}$.

$\mathrm{A}$ área destinada ao acolhimento e à classificação de risco nos setores de urgência do H GOF e - H R estava adaptada, nesteúltimo de modo adequado (oito dos dez itens presentes). Já o setor de urgências do HGV, apesar de ter passado por reforma estrutural recente, não contava com al guns elementos importantes de ambiência, como sala de apoio aos familiares e sala de ouvidoria. No HGOF, não se aplicavam as rotinas, enquanto que no HGV eno HR, o acolhimento e a classificação de risco eram realizados apenas em alguns períodos, a depender da disponibilidadeem quantidade da equipe de enfermagem. Defato, o principal entrave à composição de equipes de acolhimento éo receio de aumento da carga de trabal ho devido ao deslocamento de profissionais de saúde para esse fim ${ }^{20}$. Franco et al. ${ }^{18}$, em experiência de implantação de acolhimento em uma unidade básica de saúde, observaram aumento de horas trabalhadas por parte de enfermeiros e técnicos de enfermagem. Este aumento, porém, foi acompanhado por acréscimo considerável da produtividade em termos de acesso do usuário ao serviço que, em última instância, traduziu-se em aumento do rendimento do trabalho.

0 acolhimento é, dentre os dispositivos preconizados pela PNH e pelo Qualisus, um dos mais estudados. A maior parte desses estudos diz respeito a implantações bem-sucedidas em serviços de saúde de atenção primária ${ }^{18,22-28}$, enquanto que apenas um tem como campo um 
Tabela 1. Grau de implantação ( $\mathrm{n}$ e \%) conforme linhas de ação e seus atributos de dois eixos do programa Qualisus em três hospitais do município do Recife, 2007.

\begin{tabular}{|c|c|c|c|c|c|c|c|}
\hline \multirow{3}{*}{$\begin{array}{l}\text { Eixos, linhas de ação e atributos } \\
\text { Ihimento, ambiência acolhedora e direito } \\
\text { dários }\end{array}$} & \multirow{3}{*}{$\begin{array}{l}\text { Pontuação } \\
\text { máxima }\end{array}$} & \multicolumn{6}{|c|}{ Hospitais } \\
\hline & & \multicolumn{2}{|c|}{$\mathrm{HR}$} & \multicolumn{2}{|c|}{ HGV } & \multicolumn{2}{|c|}{ HGOF } \\
\hline & & 196 & $(78)^{1}$ & 101 & $(40)^{3}$ & 101 & $(40)^{3}$ \\
\hline 1.1 Acolhimento com classificação de risco: & 50 & 26 & $(52)^{2}$ & 21 & $(42)^{3}$ & 21 & $(42)^{3}$ \\
\hline 1.1.1 Área física: & 10 & 6 & $(60)^{2}$ & 6 & $(60)^{2}$ & 6 & $(60)^{2}$ \\
\hline 1.1.2 Recursos humanos: & 20 & 10 & $(50)^{3}$ & 10 & $(50)^{3}$ & 10 & $(50)^{3}$ \\
\hline 1.1.3 Aplicação de rotina: & 20 & 10 & $(50)^{3}$ & 5 & $(25)^{3}$ & 5 & $(25)^{3}$ \\
\hline $\begin{array}{l}1.2 \text { Garantia ao usuário à alimentação } \\
\text { adequada: }\end{array}$ & 50 & 50 & $(100)^{1}$ & 50 & $(100)^{1}$ & 50 & $(100)^{1}$ \\
\hline $\begin{array}{l}1.3 \text { Garantia ao usuário a acompanhante em } \\
\text { consultas e área de observação: }\end{array}$ & 50 & 40 & $(80)^{1}$ & 20 & $(40)^{3}$ & 20 & $(40)^{3}$ \\
\hline 1.3.1 Área física: & 10 & 0 & $(0)^{3}$ & 0 & $(0)^{3}$ & 0 & $(0)^{3}$ \\
\hline 1.3.2 Aplicação de rotina: & 40 & 40 & $(100)^{1}$ & 20 & $(50)^{3}$ & 20 & 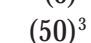 \\
\hline $\begin{array}{l}\text { 1.4 Estabelecimento de visitas abertas } \\
\text { agendadas pelos cuidadores: }\end{array}$ & 50 & 50 & $(100)^{1}$ & 0 & $(0)^{3}$ & 0 & $(0)^{3}$ \\
\hline 1.5 Formação de gru & 50 & 30 & $(60)^{2}$ & 10 & $(20)^{3}$ & 10 & $(20)^{3}$ \\
\hline 1.5.1 Recursos $h$ & 20 & 10 & $(50)^{3}$ & 10 & $(50)^{3}$ & 10 & $(50)^{3}-12(-1)$ \\
\hline 1.5.2 Aplicação de rotina: & 30 & 20 & $(67)^{2}$ & 0 & $(0)^{3}$ & 0 & $(0)^{3}$ \\
\hline 2. Resolu & 250 & 170 & $(68)^{2}$ & 185 & $(74)^{2}$ & 185 & $(74)^{2}$ \\
\hline $\begin{array}{l}\text { 2.1 Garantia de quantidade de profissionais } \\
\text { adequados à demanda: }\end{array}$ & 40 & 10 & $(25)^{3}$ & 10 & $(25)^{3}$ & 10 & $(25)^{3}$ \\
\hline 2.2 Normalização de condutas médicas: & 35 & 0 & $(0)^{3}$ & 0 & $(0)^{3}$ & 0 & $(0)^{3}$ \\
\hline 2.3 Adequação da estrutura física: & 35 & 20 & $(57)^{2}$ & 35 & $(100)^{1}$ & 35 & $(100)^{1}$ \\
\hline $\begin{array}{l}\text { 2.4 Adequação de equipamentos na sala de } \\
\text { estabilização: }\end{array}$ & 35 & 35 & $(100)^{1}$ & 35 & $(100)^{1}$ & 35 & $(100)^{1}$ \\
\hline $\begin{array}{l}2.5 \text { Organização de retaguardas de } \\
\text { especialidades médicas: }\end{array}$ & 35 & 35 & $(100)^{1}$ & 35 & $(100)^{1}$ & 35 & $(100)^{1}$ \\
\hline $\begin{array}{l}2.6 \text { Adequação do serviço de apoio diagnóstico } \\
\text { e terapêutico: }\end{array}$ & 35 & 35 & $(100)^{1}$ & 35 & $(100)^{1}$ & 35 & $(100)^{1}$ \\
\hline 2.7 Implantação de central de equipamentos: & 35 & 35 & $(100)^{1}$ & 35 & $(100)^{1}$ & 35 & $(100)^{1}$ \\
\hline Total & 500 & 366 & $(73)^{2}$ & 286 & $(57)^{2}$ & 286 & $(57)^{2}$ \\
\hline
\end{tabular}

Obs.: HR: H ospital da Restauração; H GV: H. Getúlio Vargas; H GOF: H. Geral O távio de Freitas.

Legenda: ${ }^{1}$ Grau deimplantação avançado; ${ }^{2}$ Grau de implantação intermediário; ${ }^{3}$ Grau de implantação incipiente.

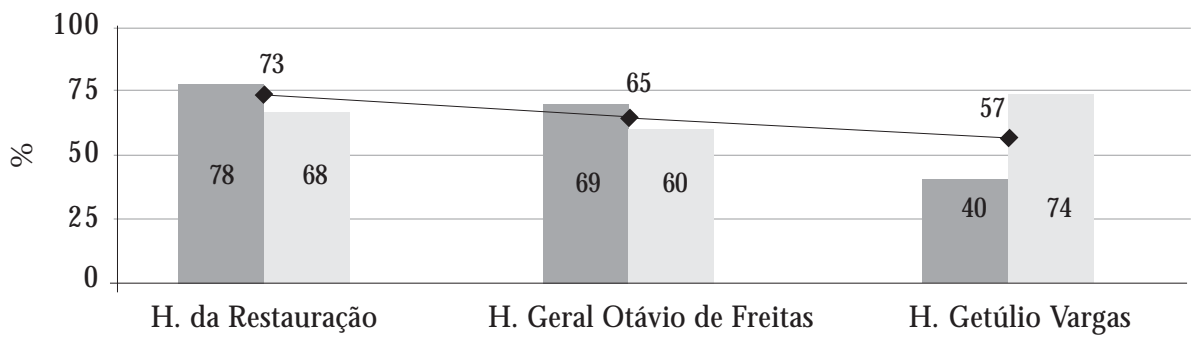

Eixo I - Acolhimento, ambiência e direitos dos usuários

Eixo II - Resolução diagnóstica e terapêutica

$\rightarrow$ Qualisus (Eixos I e II)

Gráfico 1. Grau de implantação dos Eixos I ell do programa Qualisus em três hospitais. Recife (PE), 2007. 
serviço de pronto-atendimento ${ }^{29}$. Já em relação ao dispositivo "Acolhimento com classificação de risco", encontramos uma pesquisa acadêmica ${ }^{30} \mathrm{e}$ relatos de experiências de implantação em serviços de saúde incluídos na PN H ${ }^{31}$ eno Qualisus ${ }^{32}$.

As três linhas de ação referentes aos direitos dos usuários do Eixo I foram as que obtiveram os maiores graus de implantação (Gráfico 2). A linha de ação referente à "Garantia ao usuário à alimentação adequada" obteve pontuação máxima nos três hospitais. Já a linha "Garantia a acompanhante em consultas e na área de observação" apresentou implantação avançada no $\mathrm{HR}$ e no HGOF (80\%), enquanto que no HGV o grau foi incipiente (40\%). N este hospital, eram apenas permitidos acompanhantes nos casos previstos por lei (crianças e idosos, por exemplo). A linha de ação "Estabelecimento de visitas abertas com horários agendados pelos cuidadores" alcançou $100 \%$ de implantação no HR e no HGOF, enquanto que no HGV o grau foi nulo.

Essas linhas trazem mais conceitos derivados da PNH aplicados aos setores de urgência ${ }^{33}$. A "Visita aberta" éo dispositivo que amplia o acesso para os visitantes, garantindo o elo entre 0 paciente, sua rede social e os outros serviços da rede de saúde. Já o "Acompanhante" representa esta rede social durante a estadia do paciente no hospital. Ambos atuam em conjunto na garantia de um ambiente mínimo de conforto ao paciente, facilitando a sua recuperação. São vários os entraves para a sustentação desses el ementos nos serviços de saúde, em especial nos setores de urgência. Entre estes, a carência deestrutura física e a concepção derepresentarem maisuma demanda potencial na rotina de trabal ho $0^{21,33,34}$. Deve-se destacar que nenhum dos hospitais oferecia infraestrutura adequada para 0 acolhimento dos acompanhantes, como mobiliário e sala de estar.

A última linha de ação do Eixo I refere-se à existência, composição e atuaçã̃o dos Grupos de Trabal ho de Humanização (GTH). Os GTH são dispositivos criados pela PNH, formados por profissionais, técnicos, gestores e usuários, com o propósito de auxiliar na melhoria da qualidade da produção de saúde e do processo de trabaIho atuando em serviços, instâncias gestoras (secretarias de saúde, distritos sanitários) einstituições afins (conselhos profissionais e entidades formadoras) ${ }^{35}$. No HR e no HGOF, o grau de implantação desta linha de ação foi considerado intermediário (60\%), enquanto que no HGV, in-

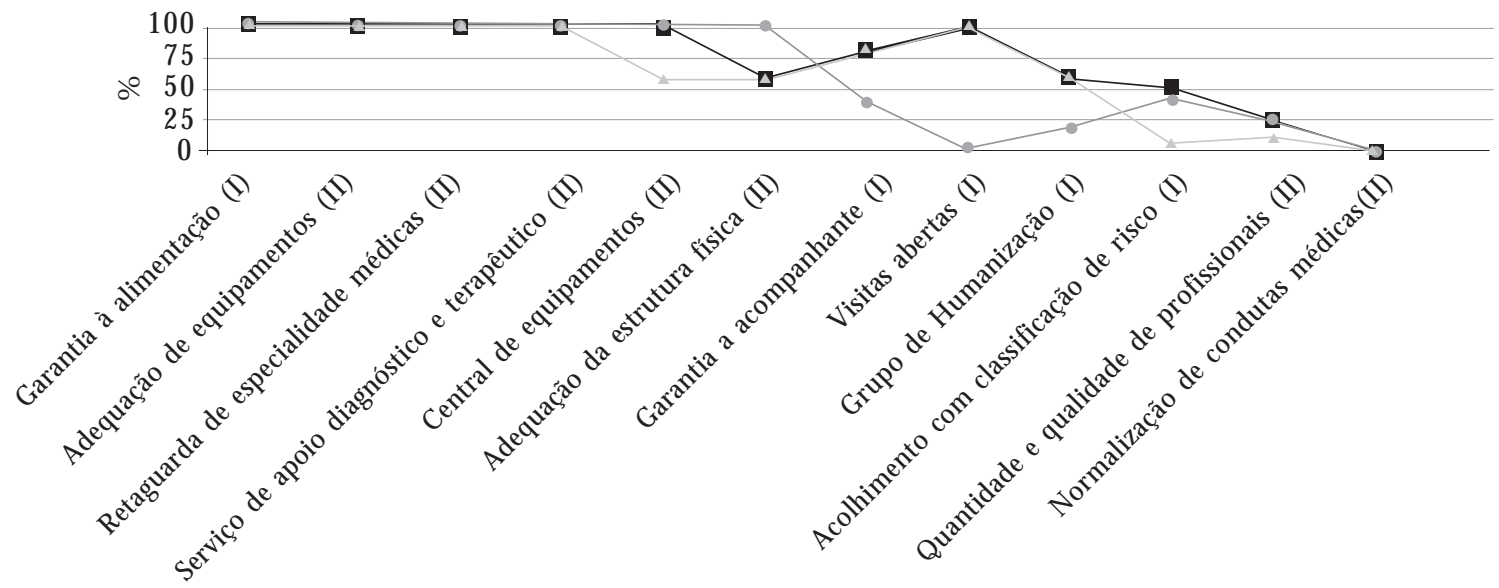

(I) Eixo I; (II) Eixo II

H. da Restauração

H. Geral Otávio de Freitas

H. Getúlio Vargas

Gráfico 1. Grau de implantação das linhas de ação pertencentes aos Eixos I e II do programa Qualisus em três hospitais. Recife (PE), 2007. 
cipiente (20\%) (Gráfico 2). Ostrêshospitais contavam com GTH formalmente constituídos, porém com número de componentes abaixo do ide al para a demanda, na opinião dos entrevistados. A penas no HR e no HGOF os GTH estavam em atividade regular.

\section{Eixo II - Resolução diagnóstica e terapêutica}

Esse eixo reúne sete linhas de ação com vistas à efetividade e resolutividade da assistência, à valorização dos trabal hadores eà redução de riscos, mesclando conceitos advindos de teorias organizacionais e da PN H,6,19. Cinco dessas referem-se estritamente a dimensões estruturais dos serviços de urgências: recursos humanos, área física e equipamentos. Já as linhas "I mplantação de central de equipamentos de suporte e monitoramento de pacientes críticos" e "N ormalização de condutas médicas" concernem também à aplicação de processos. 0 grau de implantação do Eixo II foi considerado intermediário nos três hospitais (HGV - 74\%; HR - 68\%; HGOF - 60\%) (Gráfico 1).

Em relação à linha de ação "Adequação da estrutura física do setor de urgência" em áreas de observação, retaguarda e estabilização, apenas 0 HGV cumpria com o preconizado (grau de implantação de $100 \%$ ). N o HR eno H GOF, os setores de urgência encontravam-se adaptados (57\% - implantação intermediária) (Gráfico 2). Até a realização desta pesquisa, apenas o setor de urgências do HGV havia passado por reforma estrutural recente. 0 Qualisus preconiza a divisão da área de emergência dos setores de urgência em níveis de complexidade, a fim de facilitar a assistência pela adequação de recursos humanos e tecnológicos. Essas salas devem ser identificadas por cores: área vermelha - destinada à estabilização de pacientes em estado grave, instáveis, que requerem atendimento imediato; área amarela - para atendimento de pacientes críticos, porém estáveis, aguardando vaga para internamento ou transferência, os quais requerem atendimento em no máximo quinze minutos; área verde - área preparada para o atendimento e observação de usuários não críticos, antes da alta, internamento hospitalar ou transferência, os quais requerem atendimento em até trinta minutos. Há ainda a área azul, destinada às consultas de baixa e média complexidade $e^{1,20}$.

Em relação às linhas de ação "Adequação de equipamentos na sala de observação e retaguarda", "Organização da retaguarda de especialida- des médicas às equipes" e "Adequação do serviço de apoio diagnóstico e terapêutico", os três hospitais obtiveram pontuação máxima (grau de implantação de 100\%) (Gráfico 2). As salas de observação e estabilização dos três serviços possuíam conjunto de equipamentos adequado as suas dimensões, porém insuficiente em relação à grande demanda verificada. Devido aos diferentes perfis de atendimento dos hospitais, não foi estabelecido um referencial único para equipamentos, equipes de retaguarda eserviços deapoio diagnóstico e terapêutico. Foi considerada para pontuação a conformidade com a demanda para cada hospital. Os três hospitais ofereciam central de equipamentos de suporte (setor de engenharia clínica) , porém, no HGOF, estefuncionava apenas no horário diurno.

Os três hospitais obtiveram pontuação nula em relação à linha de ação "Normalização de condutas médicas", ou seja, nenhum deles seguia qualquer guia de manejo diagnóstico ou terapêutico, clínico ou cirúrgico. Acredita-se que as normalizações de assistência médica com base em evidências científicas contribuam para a qualificação de serviços através da redução de erros, da variabilidade de condutase, consequentemente, dos custos ${ }^{6,36}$.

Por fim, a linha de ação "Garantia de quantidade e qualidade de profissionais adequados à demanda" apresentou grau de implantação incipiente nos três hospitais (HR e HGV: $25 \%$; HGOF: $13 \%$ ) (Gráfico 2). A pesar de serem considerados de alta complexidade, possuidores de diversas equipes de especialidades e de um parque tecnológico avançado, os setores de urgência dos três hospitais apresentavam insuficiência de recursos humanos, tanto de nível médio e como denível superior. A penas as equipes terceirizadas (recepção e segurança) apresentavam quadro funcional completo. 0 setor de urgências do H GOF foi o que mostrou o maior déficit de profissionais, com pouco mais de $60 \%$ do seu quadro preenchido.

\section{Consideraçõesfinais}

Nesteestudo inédito, avaliou-sea introdução por meio de um programa ministerial de melhorias estruturais e inovações organizacionais complexas em serviços deurgência e emergência degrandes hospitais públicos, setores considerados como pontos críticos do SUS.

Pelos resultados apresentados, verificamos que a implantação do Qualisus alcançou grau 
intermediário nos três hospitais. Considerandose os eixos em separado, observou-se que as linhas de ação do Eixo I (acolhimento, ambiência e direito dos usuários) obtiveram maior grau de implantação que as do Eixo II (resolutividade diagnóstica e terapêutica) em dois dos três hospitais. A penas quatro das doze linhas de ação alcançaram implantação completa. A linha"Normalização decondutas médicas" apresentou grau de implantação nulo nos três hospitais. Dessa forma, este artigo evidencia que o programa Qualisus ainda não foi adequadamente implantado, indicando a necessidade da continuidade de investimentos em recursos físicos e humanos, assim como no aprimoramento das tecnologias organizacionais e das relações interpessoais nos serviços hospitalares de urgência.

Uma vez que hospitais de outras regiões me tropolitanas também participaram do programa Qualisus, seria útil nesses casos a verificação do grau de sua implantação por meio do emprego de métodos avaliativos, tendo em vista a diversidade regional, organizacional, econômica e social que caracteriza o país. Evidencia-se assim a necessidade e importância da institucionalização da prática da avaliação em saúde como auxílio à tomada de decisões para mudanças ou ajustes na condução de programas públicos.

\section{Colaboradores}

FAR Gusmão-filho participou da formulação do objetivo, metodologia, coleta e análise dos dados e redação do texto. EF Carvalho contribuiu na formulação do objetivo e metodologia e ainda participou da redação do texto. JLAC A raújo Júnior participou da formulação do objetivo e metodologia. 


\section{Referências}

1. Organização Pan-Americana de Saúde. Estratégia de Continuidade e Expansão das A tividades do Qualisus. Recife: OPAS; 2005

2. Gouveia GC, Souza WV, Luna CF, Souza-Júnior PRB, Szwarcwald CL. Health care users' satisfaction in Brazil, 2003. Cad Saude Publica 2005;21:S109-S118.

3. Conselho Nacional de Secretários Estaduais de Saúde. Saúde na opinião dos brasileiros. Brasília: Editora do Ministério da Saúde; 2003.

4. Conselho Federal de M edicina. Resolução 1.451 de 10 de março de 1995. Define os conceitos de urgência e emergência e equipe médica e equipamentos para os pronto-socorros.Diário Oficial da União 1995; 17 mar.

5. Brasil. M inistério da Saúde. Secretaria-Executiva. Qualisus - Política de qualificação da atenção à saúde. Brasília: M inistério da Saúde; 2004.

6. Organização Pan-Americana de Saúde. M etodologia de intervenção do Qualisus. Recife: OPAS; 2005

7. Brasil. M inistério da Saúde. Portaria GM/MS 1.863 de 29 de setembro de 2003. Institui a Política Nacional de Atenção às U rgências, a ser implantada em todas as unidades federadas, respeitadas as competências das três esferas de gestão. Diário Oficial da U nião 2003; 29 set.

8. Brasil. Ministério da Saúde. Secretaria de Atenção à Saúde. Núcleo Técnico da Política Nacional de Humanização. HumanizaSU S: documento base para gestores e trabalhadores do SUS. 3a ed. Brasília: Editora do Ministério da Saúde; 2006.

9. Brasil. Ministério da Saúde. Portaria GM/M S 3.125 de 7 de dezembro de 2006. Institui o Programa de Qualificação da Atenção Hospitalar de U rgência no Sistema Ú nico de Saúde - Programa QualiSUSU rgência - e define competências. Diário Oficial da União 2006; 7 dez.

10. Contandriopoulos AP, Champagne F, Denis JL, Pineault R. A avaliação na área da saúde: conceitos e métodos. In: Hartz ZM A, organizador. Avaliação em saúde: dos modelos conceituais à prática na análise da implantação de programas. Rio de Janeiro: Fiocruz; 1997. p. 29-47.

11. Donabedian A. Evaluating the quality of medical care. M ilbank M em Fund Q 1966; 44 (Supl):166 206.

12. Furtado BMASM. Perfil da clientela da emergência do H ospital da Restauração: uma análise dos possíveis impactos após a municipalização dos serviços de saúde [dissertação]. Recife (PE): Centro de Pesquisa Aggeu M agalhães; 2003.

13. Organização Pan-Americana de Saúde. Análise dos resultados alcançados pelo Qualisus. Recife: OPAS 2006.

14. Santos JS. Instrumento de conhecimento da organização das portas hospitalares de urgência para subsidiar a Política de Qualificação dos Hospitais de U rgência. In: Organização Pan-Americana de Saúde. Estratégia de continuidade e expansão das atividades do Qualisus. Recife: OPAS; 2005. p. 40-62.

15. Gomes M CPA, Pinheiros R. Acolhimento e vínculo: práticas de integralidade na gestão do cuidado em saúde em grandes centros urbanos. Interface (Botucatu) 2005; 9:287-301.
16. Teixeira RR. 0 acolhimento num serviço de saúde entendido como uma rede de conversações. In: Pinheiro R, Mattos RA, organizador. Construção da integralidade: cotidiano, saberes e práticas de saúde. Rio de Janeiro: IMS-UERJ/ABRASC 0; 2003.

17. M erhy EE. Saúde: a cartografia do trabalho vivo. São Paulo: Hucitec; 2002.

18. Franco TB, Bueno WS, M erhy EE. O acolhimento e os processos de trabalho em saúde: o caso de Betim, Minas Gerais, Brasil. Cad Saude Publica 1999;15:345-353.

19. Brasil. M inistério da Saúde. Secretaria de Atenção à Saúde. Núcleo Técnico da Política Nacional de Humanização. Acolhimento nas práticas de produção de saúde. 2ª ed. Brasília: Ministério da Saúde; 2006.

20. Brasil. M inistério da Saúde. Secretaria-Executiva. Núcleo Técnico da Política Nacional de Humanização. HumanizaSU S: acolhimento com avaliação e classificação de risco: um paradigma ético-estético no fazer em saúde. Brasília: M inistério da Saúde; 2004.

21. Brasil. M inistério da Saúde. Secretaria-Executiva. Núcleo Técnico da Política Nacional de Humanização. HumanizaSU S: ambiência. Brasília: M inistério da Saúde; 2004.

22. Takemoto MLS, Silva EM . Acolhimento e transformações no processo de trabalho de enfermagem em unidades básicas de saúde de Campinas, São Paulo, Brasil. Cad Saude Publica 2007; 23:331-340.

23. Lima MADS, Ramos DD, Rosa RB, Nauderer TM, Davis R. Acesso e acolhimento em unidades de saúde na visão dos usuários. Acta paul enferm 2007; 20:12-17.

24. Scholze AS, Ávila LH, Silva M M, Dacoreggio STK. A implantação do acolhimento no processo de trabalho de equipes de saúde da família. Revista Espaco para a Saúde [periódico na Internet] 2006 [acessado 2008 jan 04];8(1):[cerca de 6 p.]. Disponível em: http://www.ccs.uel.br/espacoparasaude/v8n1/ v8n1 artigo 2.pdf

25. Solla JJSP. Acolhimento no sistema municipal de saúde. Rev. Bras. Saude M atern. Infant. 2005; 5:493503.

26. Schimith MD, Lima MADS. Acolhimento e vínculo em uma equipe do Programa Saúde da Família. Cad Saude Publica 2004; 20:1487-1494.

27. Ramos DD, Lima MADS. Acesso e acolhimento aos usuários em uma unidade de saúde de Porto Alegre, Rio Grande do Sul, Brasil. Cad Saude Publica 2003; 19:27-34.

28. Camelo SHH, Angerami ELS, Silva EM, Mishima SM. A colhimento à clientela: estudo em unidades básicas de saúde no município de Ribeirão Preto. Rev Latino-am Enfermagem 2000; 8:30-37.

29. M arques GQ, Lima MADS. Demandas de usuários a um serviço de pronto atendimento e seu acolhimento ao sistema de saúde. Rev Latino-am Enfermagem 2007; 15:1-8.

30. Coêlho BP. 0 reencantamento do concreto e as apostas nas mudanças nos M odelos de Atenção e de Gestão do SUS ( 0 caso do Instituto Hospitalar General Edson Ramalho/João Pessoa/Paraíba) [dissertação]. Recife $(\mathrm{PE})$ : Centro de Pesquisas Aggeu M agalhães, Fiocruz; 2006 
31. Brasil. M inistério da Saúde. Secretaria da Atenção à Saúde. Política Nacional de Humanização. A humanização no Hospital Municipal Odilon Behrens: um modo de fazer includente e participativo - Belo Horizonte, M G. [site da Internet] 2006 [acessado 2008 jan 4]. Disponível em: http://portal.saude.gov.br/ portal/arquivos/pdf/HOB 02-10.pdf

32. Brasil. Ministério da Saúde. Secretaria da Atenção à Saúde. Política Nacional de Humanização. AcoIhimento com classificação de risco na emergência do Hospital Nossa Senhora da Conceição - Grupo Hospitalar Conceição - Porto Alegre, RS. [site da Internet] 2006 [acessado 2008 Jan 4].Disponível em: http://portal.saude.gov.br/portal/arquivos/pdf/ GHC_02-10.pdf

33. Brasil. M inistério da Saúde. Secretaria de Atenção à Saúde. Núcleo Técnico da Política Nacional de Humanização. Visita aberta e direito a acompanhante. Brasília: Ministério da Saúde; 2006.
34. Brasil. M inistério da Saúde. Secretaria da Atenção à Saúde. Política Nacional de Humanização. A humanização da atenção à saúde no Hospital Sofia Feldman - Belo Horizonte, M G; 2006. [site da Internet] [acessado 2008 jan 4].Disponível em: http:/ /portal.saude.gov.br/portal/arquivos/pdf/sofia_0210.pdf

35. Brasil. M inistério da Saúde. Secretaria de Atenção à Saúde. Núcleo Técnico da Política Nacional de Humanização. Grupo de Trabalho de Humanização. Braślia: M inistério da Saúde; 2006.

36. Walker RD, Howard M O, Lambert MD. Medical Practice Guidelines. West J M ed 1994; 161:39-44.

Artigo recebido em 28/01/2008

Aprovado em 03/07/2008

Versão final apresentada em18/07/2008 